\title{
MYRRH ADDITION TO A CONVENTIONAL GLASS-IONOMER CEMENT: INFLUENCE ON PHYSICAL AND ANTIBACTERIAL PROPERTIES
}

\author{
Reham M. Abdallah*, Amr M. Abdelghany ${ }^{* * *}$ and Neven S. Aref ***
}

\begin{abstract}
Purpose: This study investigated the effect of incorporating myrrh (Commiphora molmol) to Glass ionomer cement (GIC) on its physical and antibacterial properties.

Materials and Methods: Myrrh powder was incorporated into the powder component of Riva GIC (SC; SDI Ltd., Bayswater, Australia) at 1, 2 and 5\% (w/w). Unblended powder was used as control. Modified GIC powder was characterized using Fourier transform infrared (FTIR). Compressive strength and young's modulus were evaluated using a Universal Testing machine. Surface microhardness was measured using Vickers microhardness tester. Solubility was calculated by means of weighing the specimens before and after immersion and desiccation.
\end{abstract}

The antibacterial activity was assessed using agar diffusion method against Bacillus subtilis, Escherichia Coli and Staphylococcus aureus. Data were analyzed by ANOVA and Tukey's tests $(p<0.05)$.

Results: Incorporation of 1, 2 and 5\% (w/w) myrrh to GIC did not affect its mechanical properties significantly $(\mathrm{P} \geq 0.05)$. On the other hand, there was a corresponding significant increase in the solubility and antibacterial activity of glass ionomer cement with the highest value against staphylococcus aureus in comparison to that of the control group $(\mathrm{P}<0.05)$.

Conclusion: Modification of GIC with low concentration of myrrh seems to produce a promising restorative material with antibacterial properties without adversely affecting its mechanical properties. This novel experimental GIC may be potentially useful for a variety of clinical applications.

KEYWORDS: Glass ionomer cement; Myrrh; Compressive strength; Hardness; Young's modulus; Solubility; Antibacterial.

\footnotetext{
* Dental Biomaterials Department, Faculty of Dentistry, Mansoura University, Mansoura, Egypt

** Spectroscopy Department, Nuclear Physics Division, Materials Science, National Research Center, Cairo, Egypt

*** Dental Biomaterials Department, Faculty of Dentistry, Mansoura University, Mansoura, Egypt
} 


\section{INTRODUCTION}

New approaches, techniques and materials have focused on maximum prevention and minimally invasive procedures in dentistry. Accordingly, Atraumatic Restorative Treatment (ART) based on the removal of carious tissue with hand instruments and restoration with an adhesive material. ${ }^{1}$ Glass ionomer cement (GIC) is the material of choice as it presents several advantages such as direct adhesion to tooth structure and base metals,,$^{2,3}$ anticariogenic properties due to release of fluoride, ${ }^{4}$ minimized microleakage at the tooth-enamel interface due to low shrinkage, thermal compatibility with tooth enamel and dentin due to low coefficient of thermal expansion similar to that of tooth structure, ${ }^{5,6}$ biological compatibility and low cytotoxicity. ${ }^{7,8}$

Today, ART does not seem to be confined to places where electricity is absent. It is also accepted by patients with dental anxiety and by children in modern clinical settings, as the sound and pressure caused by rotary instruments is omitted and local anesthesia is not needed. ${ }^{9}$ Although GIC has many advantages, its use as a restorative material has still been questioned because of secondary caries and low mechanical properties. ${ }^{10}$ The bacteria can invade the interface of the restoration and dentine through microleakage to create secondary caries, which might progress over time and lead to the failure of the GIC restoration. ${ }^{11}$

Accordingly, this indicates that the fluoride released from GICs is not sufficiently potent to inhibit bacterial growth or combat the effects of bacterial destruction. Although numerous efforts have been made to improve the antibacterial activity of dental restoratives, most have been focused on the release or the slow release of various incorporated low-molecular-weight antibacterial agents, such as antibiotics, zinc ions, silver ions, iodine, and chlorhexidine (CHX). However, the release or the slow release of antibacterial agents can lead to a reduction in the mechanical properties of the restoratives over time, short-term effectiveness and possible toxicity to the surrounding tissues, if the dose or release is not properly controlled. ${ }^{12-14}$

Myrrh is a commercially used resin of different Commiphora species, mostly of Commiphora molmol, Engler, Burseraceae, obtained after injuring the bark of the small trees, growing wild in Somalia, Jemen and Arabia. It is mainly used in toothpastes and tinctures for the treatment of gingivitis and is composed of three main constituents: (i) the essential oil (2-10\%); (ii) the EtOH soluble resin (25-40\%); and (iii) the water soluble gum (30-60\%). Despite the fact that myrrh is one of the oldest remedies, especially in oriental medicine, little is known about its exact chemical composition. Mainly for the presence of essential oil, it has been widely used until today for the treatment of inflammatory diseases of the mucosa of mouth and throat, as well as for its disinfecting and astringent properties. ${ }^{15}$

Mouthrinses and toothpastes containing myrrh were successful in treating gingivitis 16,17 and in reducing 4-day plaque regrowth. ${ }^{18}$ Two sesquiterpenic compounds isolated from a hexane extract of myrrh resin exhibited antimicrobial activity towards several microorganisms (Escherichia coli, Staphylococcus aureus, Pseudomonas aeruginosa and Candida albicans). They also had local anesthetic activity and were not toxic to human fibroblasts (source not specified) ${ }^{19}$ However, there were no identified researches on the influence of incorporation of myrrh into GIC. Therefore, this study aimed to investigate the addition of myrrh on the physical and antibacterial properties of a conventional GIC. The null hypothesis is that the incorporation of increasing concentrations of myrrh into GIC does not affect its physical and antibacterial properties.

\section{MATERIAL AND METHODS}

A conventional glass-ionomer powder (Riva SC; SDI Ltd., Bayswater, Australia) was blended with different proportions with myrrh. Powders were made by mixing made by mixing 1,2 and $5 \%(w / w)$ 
myrrhpowder with the glass ionomer powder by hand using mortar and pestle for $10 \mathrm{~min}$. Unblended powder was used as the control for all tests. The recommended powder/liquid (P/L) ratio of $1.8 / 1$ for glass ionomer luting cement was used in all of the prepared specimens.

\section{Glass ionomer powder characterization}

Fourier transform infrared (FTIR) absorption spectra of the powdered samples were measured at room temperature $\left(\sim 20^{\circ} \mathrm{C}\right)$ in the wavelength range $4000-400 \mathrm{~cm}^{-1}$ using FTIR spectrometer (type Mattson 5000, USA) to assay the molecular interaction of the cement. The fine powder of the samples was mixed with $\mathrm{KBr}$ in the ratio 1:100 for quantitative study and the mixture was subjected to a load of 5 tons $/ \mathrm{cm}^{2}$ in an evacuble die to produce clear homogeneous discs. Then, the infra red (IR) absorption spectra were immediately measured after preparing the discs to avoid moisture attack. The measurements were taken for the studied samples before and after immersion in the phosphate solution.

\section{Compressive strength test}

Twenty cylindrical specimens were prepared in a stainless steel split mold (4 $\mathrm{mm}$ in diameter and $6 \mathrm{~mm}$ in height) according to ISO standard. ${ }^{20}$ The compressive strength (Cs) (MPa) of the specimens was measured using the universal testing machine at a crosshead speed of $0.5 \mathrm{~mm} / \mathrm{min}$ and it was calculated using the following equation:

$$
\mathrm{Cs}=4 \mathrm{P}_{\mathrm{f}} / \pi \mathrm{D}^{2}
$$

Where $\mathrm{P}_{\mathrm{f}}$ is the load $(\mathrm{N})$ at fracture and $\mathrm{D}$ is the diameter of specimen $(\mathrm{mm}){ }^{21}$

\section{Surface microhardness test}

A stainless-steel mold with inner dimensions of $6 \pm 0.1 \mathrm{~mm}$ diameter and $3 \pm 0.1 \mathrm{~mm}$ thickness was used for preparing 20 disk shaped specimens. Within 60 seconds after the end of mixing, the GICs were packed into the conditioned molds slightly in excess and covered with strips. One hour after the end of mixing, the specimens were removed from their molds and stored at $37 \pm 1^{\circ} \mathrm{C}$ in water prior to testing. After the storage time of 24 hours, the Vickers hardness numbers (VHN), were obtained using a micro-indentation tester (MMT-3 Digital Hardness Tester, Buehler Ltd., Lake Bluff, IL) by applying a load of $29.42 \mathrm{~N}$ on the specimens for 30 seconds. Five indentation measurements were carried out and averaged for each specimen. ${ }^{22}$

\section{Solubility test}

Twenty disc-shaped specimens were prepared in a stainless steel mold $(10 \mathrm{~mm}$ in diameter and $1 \mathrm{~mm}$ in thickness) ${ }^{23}$ All specimens were conditioned by placing them in a desiccator containing calcium sulfate at $37^{\circ} \mathrm{C}$ until a constant weight had been achieved $\left(\boldsymbol{m}_{\mathbf{0}}\right)$ using an electronic balance (Sartorius MCI Research RC Z10 D, Sartorius AG, Gottingen, Germany). Then, the disks were placed in a glass vial containing $100 \mathrm{~mL}$ of artificial saliva. The vials were placed in an incubator at $37^{\circ} \mathrm{C}$ at intervals ( $24 \mathrm{~h}$ and subsequently at 2-day intervals). Finally, the discs were removed from the artificial saliva and redesiccated and reweighed until a constant weight had been achieved for the last time $\left(\boldsymbol{m}_{\mathbf{1}}\right)$. These steps were carried out to evaluate solubility $(S)$ according to Oysaed and Ruyter formula:

$$
S=m_{0}-m_{1} / V
$$

Where $\boldsymbol{m}_{\mathbf{0}}$ is the sample weight before immersion and $\boldsymbol{m}_{\mathbf{1}}$ is the sample weight after immersion and desiccation and $\boldsymbol{V}$ is the sample volume. ${ }^{24}$

\section{Antibacterial test}

The antibacterial effects of the tested specimens against Bacillus subtilis, Escherichia Coli and Staphylococcus aureus were assessed using agar diffusion test. Briefly, $100 \mathrm{~mL}$ of the respective bacteria were grown in $10 \mathrm{~mL}$ of fresh media until they reached account of approximately 108 cells/mL. A $100 \mathrm{~mL}$ of microbial suspension was spread onto agar plates corresponding to the broth in which they were maintained. Isolated colonies of 
each organism that might be playing a pathogenic role should be selected from primary agar plates and tested for susceptibility by disk diffusion method. Plates inoculated with the different microorganisms were incubated at $35-37^{\circ} \mathrm{C}$ for $24-48$ hours, then the diameters of the inhibition zones were measured in millimeters. Standard disks of unmodified GIC and myrrh served as controls for anti-microbial activity.

All data were analyzed using two-way ANOVA and Tukey post-hoc analysis with a significance factor of $\alpha=0.05$.

\section{RESULTS}

\section{Powder characteriazation}

FTIR spectra of unmodified glass ionomer powder and modified ones with 1,2 and $5 \%(\mathrm{w} / \mathrm{w})$ of myrrh are shown in Fig. 1. No obvious peak shift was observed with increasing myrrh content.

\section{Mechanical properties evaluation}

The mean and standard deviation values for compressive strength, surface microhardness and Young's modulus are presented in Table 1. One-way analysis of variance identified non significant differences between mean values of compressive strength, surface microhardness and Young's modulus of the tested groups $(\mathrm{P} \geq 0.05)$.

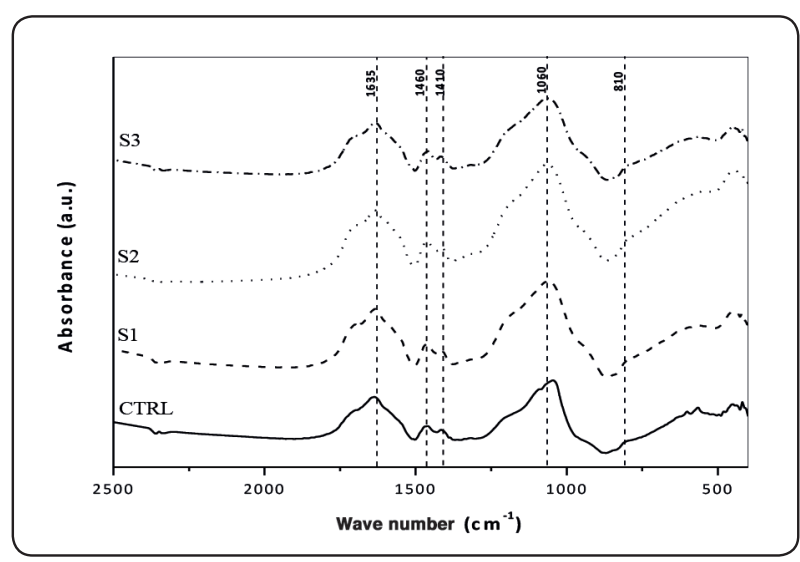

Fig. (1) IR absorption spectra of unmodified and modified GIC powder with 1,2 and $5 \%(\mathrm{w} / \mathrm{w})$ myrrh.

\section{Compressive strength}

The values of 1,2 and 5\% (w/w) myrrh addition to glass ionomer cement were relatively lower than those of the control group. However, the differences were not statistically significant $(\mathrm{P} \geq 0.05)$.

\section{Surface microhardness}

All of the tested groups had microhardness values comparable to the control group.

\section{Young's modulus}

The values of $1 \%$ and $2 \%(\mathrm{w} / \mathrm{w})$ myrrh added groups tended to be comparable to that of the control group. On the other hand, $5 \%(\mathrm{w} / \mathrm{w})$ myrrh added

TABLE (1) Mean (standard deviation) of mechanical properties of glass ionomer with myrrh incorporation and Tukey's analysis.

\begin{tabular}{lccc}
\hline \multicolumn{1}{c}{ Group } & $\begin{array}{c}\text { Compressive strength } \\
(\mathbf{M P a})\end{array}$ & $\begin{array}{c}\text { Surface microhardness } \\
(\mathbf{V H N})\end{array}$ & $\begin{array}{c}\text { Young's modulus } \\
(\mathbf{G P a})\end{array}$ \\
\hline GI-control & $91.96(2.46)^{\mathrm{a}}$ & $444(1.41)^{\mathrm{b}}$ & $669.64(8.02)^{\mathrm{c}}$ \\
GI-1\% (w/w) myrrh & $83.64(4.77)^{\mathrm{a}}$ & $41.83(2.14)^{\mathrm{b}}$ & $673.72(20.69)^{\mathrm{c}}$ \\
GI-2\% (w/w) myrrh & $82.04(5.24)^{\mathrm{a}}$ & $44(2.76)^{\mathrm{b}}$ & $667.89(7.15)^{\mathrm{c}}$ \\
& $84.93(6.92)^{\mathrm{a}}$ & $41.17(2.32)^{\mathrm{b}}$ & $716.09(41.31)^{\mathrm{c}}$ \\
\hline
\end{tabular}

Mean values for each property represented with the same superscript letter(column) are not significantly different (P $\geq 0.05)$, whilst the mean values with different letters are significantly different $(P<0.05)$. 
group tended to have relatively greater value than that of the control group. However, this increase was not statistically significant $(\mathrm{P} \geq 0.05)$.

\section{Solubility test}

The solubility values of GIC groups are presented in Table 2. The values of 1,2 and $5 \%(w / w)$ myrrh added groups showed significant increase in comparison to that of the control group $(\mathrm{P}<0.05)$.

\section{Antibacterial test}

Mean values and standard deviations of inhibition zones (mm) against different strains of bacteria of the different groups are shown in Table 3. The results indicated that group of myrrh powder had the highest mean value against all types of bacteria with the highest value against Bacillus subtilis (22) while the unmodified GI powder group had the lowest (0). Two-way ANOVA test showed that there was a significant difference between inhibition zone values of the studied groups $(\mathrm{P}<0.05)$. LSD test showed that incorporating myrrh powder into glass ionomer powder by ratio 1,2 and $5 \%(\mathrm{w} / \mathrm{w})$ showed significant increase in the antibacterial activity of glass ionomer cement with the highest value against staphylococcus aureus as shown in Table 3.

TABLE (2) Mean (standard deviation) of solubility $\left(\mu \mathrm{g} / \mathrm{mm}^{3}\right)$ of glass ionomer with myrrh incorporation and Tukey's analysis.

\begin{tabular}{cc}
\hline Group & Solubility $\left(\boldsymbol{\mu g} / \mathbf{m m}^{3}\right)$ \\
\hline GI-control & $0.0138(0.00019)^{\mathrm{d}}$ \\
GI-1\%(w/w) myrrh & $0.0142(0.00021)^{\mathrm{c}}$ \\
GI-2\%(w/w) myrrh & $0.0146(0.000156)^{\mathrm{b}}$ \\
GI-5\%(w/w) myrrh & $0.0195(0.00025)^{\mathrm{a}}$ \\
\hline
\end{tabular}

Different letters indicate statistically significant differences among materials $(\boldsymbol{P}<0.05)$.

TABLE (3) Mean (standard deviations) and LSD of inhibition zones ( $\mathrm{mm}$ ) against different bacteria.

\begin{tabular}{|c|c|c|c|}
\hline Group & Bacillus subtilis & E.Coli & Staphylococcus aureus $^{\circ}$ \\
\hline Unmodified GI powder & $0(0)^{\mathrm{d}}$ & $0(0)^{\mathrm{d}}$ & $0(0)^{\mathrm{e}}$ \\
\hline Myrrh powder & $22(1.84)^{\mathrm{a}}$ & $20(1.88)^{\mathrm{a}}$ & $21(1.45)^{\mathrm{a}}$ \\
\hline GI-1\%(w/w) myrrh & $2(0.25)^{\mathrm{c}}$ & $3(0.39)^{\mathrm{c}}$ & $2(0.26)^{\mathrm{d}}$ \\
\hline GI-2\% (w/w) myrrh & $3(0.34)^{\mathrm{c}}$ & $4(0.37)^{\mathrm{c}}$ & $5(0.25)^{\mathrm{c}}$ \\
\hline GI-5\% (w/w) myrrh & $5(0.46)^{\mathrm{b}}$ & $6(0.25)^{\mathrm{b}}$ & $8(0.29)^{\mathrm{b}}$ \\
\hline LSD & 1.15 & 1.66 & 0.90 \\
\hline
\end{tabular}

Means with the same superscripted letter are not significantly different at $P \geq 0.05$. 


\section{DISCUSSION}

One of the most important criteria for success of dental materials is to inhibit recurrent caries formation. GICs are characterized by their ability to prevent caries ${ }^{25}$ because of fluoride release ${ }^{26}$ and their clinical adhesion to dental hard tissues. Vermeersch and colleagues ${ }^{27}$ proposed that GICs have antimicrobial property because of fluoride release and/or acidity. The results of previous investigations about the antibacterial effects of both fluoride and low $\mathrm{pH}$ are controversial. ${ }^{25}$ Moreover, the decrease in the bacterial counts as a result of placement of conventional GICs in cavities is not reliable ${ }^{14}$; thus, antibacterial GICs would provide an alternative approach.

Takahashi and colleagues ${ }^{14}$ concluded that $1 \%$ chlorohexidine diacetate addition was optimal to give appropriate physical and antibacterial properties to glass ionomer cement. Regarding the previous results, myrrh was selected, which has been widely used until today for the treatment of inflammatory diseases of the mucosa of the mouth and throat as well as disinfecting and astringent properties, ${ }^{15}$ to be used as an antimicrobial agent, in the form of a powder to be incorporated into the conventional GIC powder.

For FTIR analysis, the peak at $1706 \mathrm{~cm}^{-1}$ was related to the $\mathrm{C}=\mathrm{O}$ stretching vibrations in the carboxylic group, whereas the peak at $1635 \mathrm{~cm}^{-1}$ was attributed to $-\mathrm{OH}$ bending vibrations of carboxylic group. In addition, the peaks at $1060 \mathrm{~cm}^{-1}$ and $810 \mathrm{~cm}^{-1}$ due to aluminum silicates were recognized. There was a shift in the peak at $1630 \mathrm{~cm}^{-1}$ with increasing the incorporated ratio of myrrh to higher wave length than that of unmodified GIC. The formation of both calcium and aluminum polysalts caused the appearance of the band at 1410 to $1460 \mathrm{~cm}^{-1}$. The silica gel formation by acidic degradation of the glass powder was indicated by the asymmetric stretching vibrations in $\mathrm{Si}-\mathrm{O}$ that appear between 940 and $1200 \mathrm{~cm}^{-1}$. $28-30$

Regarding the mechanical properties evaluation, there was an insignificant decrease in compressive strength of 1, 2 and 5\% (w/w) myrrh added GIC powders in comparison to the control group. This denotes an interference of the myrrh particles with the normal GIC reaction. It may be due to lack of cross linking of these particles, which are likely to weaken the GIC. ${ }^{31}$

The slight insignificant enhancement in compressive strength of $5 \%(\mathrm{w} / \mathrm{w})$ myrrh added group in comparison to the other $1 \%$ and $2 \%$ (w/w) myrrh added groups can be attributed to the increased amount of small sizes of myrrh particles incorporated along with the glass powder into the GIC material. The presence of these small particles can consequently occupy the empty spaces between the GIC glass particles and act as additional bonding sites for the polyacrylic polymer thereby reinforcing the GIC material ${ }^{32,33}$

The slight decrease in hardness of glass ionomer at concentrations of $1 \%$ and $5 \%$ myrrh, while not statistically significant, may be due to the weakening of the bulk of the cement that led to decreased ability to resist indentation, and hence reduced hardness. ${ }^{34}$

The insignificant improvement of the stiffness of GIC may indicate increased homogeneity, which leads to polysalt bridge formation and cross linking in the final set material when myrrh is added to the GIC. ${ }^{32}$

Solubility is the ability of a substance to dissolve in another, expressed as the concentration of saturated solution of the former in the latter. When solubility is tested, there is no particle in suspension (the solvent remains limpid). ${ }^{35}$

Factors which govern the dissolution of the material are the particle size, powder/ liquid ratio, mixing technique, contamination, medium $\mathrm{pH}$, exposure time to $\mathrm{pH}$ medium and status of oral hygiene..$^{36}$

The results of this study exhibited significant increase in solubility of glass ionomer cement with the corresponding increase in the percentage of incorporated myrrh in comparison to that of the control group. 
Accordingly, myrrh should be kept as low as possible, as the added myrrh does not contribute to the formation of the glass ionomer network, and therefore, high amounts of myrrh would weaken the scaffold and increase the liability for leaching of components and the corresponding dissolution and solubility of the antibacterial glass ionomer. According to these facts and results, it would be more appropriate to use the lowest concentration of incorporated myrrh for further development in antibacterial glass ionomer cement.

As for the antibacterial test, agar plate diffusion was the method of choice for this study because it allowed both set and unset materials to be assayed. ${ }^{37}$ Moreover; the process is relatively inexpensive and can be performed rapidly and easily with a large number of specimens. However, there are also some limitations with this test method. One of the main concerns is the inability of the method to distinguish between bacteriostatic and bactericidal effects, so the test does not provide any information about the viability of the test microorganisms within the inhibition zone. Moreover, the test does not simulate the clinical condition where multiple species of bacteria will be growing in complex biofilms. ${ }^{38}$

It was found that the antimicrobial activity was dependent upon the concentration of the disinfectant added to GICs. ${ }^{39}$ In agar-diffusion tests, it was found for all the tested groups that the increase in sizes of inhibition zones produced against Staphylococcus aureus, Escherichia coli and Bacillus subtilis was clearly dependent upon the corresponding increase in concentration of the myrrh incorporated to the GIC.

The antibacterial activity of myrrh against different types of bacteria may be related to the presence of essential oils in its composition which could be inhibitory to the growth of bacteria. This could be explained as the essential oils are highly volatile at the room temperature and this gaseous contact with bacteria may express its antibacterial activity. It has been also reported that the cell growth and reproduction could be affected by increasing the concentration of myrrh. ${ }^{40,41}$ This is in agreement with another study which confirmed the activity of myrrh essential oils against candida albicans. ${ }^{42}$ In another study, it has been reported that the antibacterial effects of the essential oil are facilitated through inducing significant morphological changes in bacterial cells along with generating reactive oxygen species within the bacterial cultures. The essential oils caused serious morphological damage to the drug resistant Staphylococcus aureus. These essential oils could be used as a safe and natural alternative to antibiotics with less incidence of showing multidrug resistance. ${ }^{43}$

\section{CONCLUSION}

The null hypothesis was rejected because both the solubility and antibacterial activity of myrrh modified glass ionomer cement increased with the corresponding increase in myrrh concentration. However, there was not any significant negative insult on its mechanical properties

\section{CONFLICT OF INTEREST}

There are no financial and personal relationships with other people or organizations that could inappropriately influence (bias) this work.

\section{REFERENCES}

1. Wang L, Lopes LG, Bresciani E, Lauris JRP, Mondelli RFL, Navarro MFL. Evaluation of Class I ART restorations in Brazilian schoolchildren: three-year results. Spec Care Dentist. 2004; 24:28-33.

2. Van Noort R. Introduction to dental materials. 2nd ed. London: Mosby; 2002.

3. Smith DC. Polyacrylic acid-based cement: adhesion to enamel and dentin. Oper Dent 1999;5:177-83.

4. Wilson AD, Nicholson JW. Acid-base cements: their biomedical and industrial applications. Cambridge: Cambridge University Press; 1993.

5. Davidson CL. Advances in glass-ionomer cements. Chicago, USA: Quintessence Pub. Co.; 1999. 
6. Mount GF. An atlas of glass-ionomer cements: a clinician's guide. 2nd ed. London: Martin Dunitz; 1994.

7. McLean JW, Nicholson JW, Wilson AD. Proposed nomenclature for glass-ionomer dental cements and related materials. Quintessence Int 1994;25:587-9.

8. Culbertson BM. New polymeric materials for use in glassionomer cements. J Dent 2006;8:556-65.

9. Phantumvanit P, Songpaisan Y, Pilot T, Frencken JE. A traumatic restorative treatment (ART): a three-year community field trial in Thailand -survival of one- surface restorations in the permanent dentition. J Public Health Dent 1996;56:141-5.

10. Dowling AH, Stomboulis A, Fleming GJ. The influence of montmorillonite clay reinforcement on the performance of a glass ionomer restorative. Journal of Dentistry 2006; 34:802-10.

11. Van Amerogen WE. Dental caries under glass ionomer restorations. Journal of Public Health Dentistry 1996; $56: 150-4$.

12. Wiegand A, Buchalla W, Attin T. Review on fluoridereleasing restorative materials - fluoride release and uptake characteristics, antibacterial activity and influence on caries formation. Dent Mater 2007; 23: 343-62.

13. Osinaga PW, Grande RH, Ballester RY, Simionato MR, Delgado Rodrigues CR, Muench A. Zinc sulfate addition to glass-ionomer-based cements: influence on physical and anti-bacterial properties, zinc and fluoride release. Dent Mater 2003; 19: 212-7.

14. Takahashi Y, Imazato S, Kaneshiro AV, Ebisu S, Frencken JE, Tay FR. Antibacterial effects and physical properties of glass-ionomer cements containing chlorhexidine for the ART approach. Dent Mater 2006; 22: 647-52.

15. Wiendl RM, Muller BM Franz G. Protuglycans from the gum exudate of myrrh. Carbohydrate Polymers1995; 28:217-26.

16. Serfaty, R., Itic, J., 1988. Comparative trial with natural herbs; mouthwash vs chlorhexidine in gingivitis. Journal of Clinical Dentistry 1, A34.

17. Yamnkell, S., Emling, R.C., 1988. Two-month evaluation of Para-dontax dentifrice. Journal of Clinical Dentistry 1, A34..

18. Moran, J., Addy, M., Roberts, S., 1992. A comparison of nat-ural product, triclosan and chlorhexidine mouthrinses on 4-day plaque regrowth. Journal of Clinical Periodontology 19, 578- 82.

19. Dolara, P., Corte, B., Ghelardini, C., Pugliese, A.M., Cerbai, E., Menichetti, S., Lo Nostro, A., 2000. Local anesthetic, antibacterial, and antifungal properties of sesquiterpines from myrrh. Planta Medica 6, 356-8.

20. ISO. ISO 9917-1: dentistry-water-based cements-part 1: powder/liquid acid-base cements. Geneva, Switzerland: International Organization for Standardization; 2007.

21. Zraikat H, Palamara JE, Messer HH, Burrow MF, Reynolds EC. The incorporation of casein phosphopeptideamorphous calcium phosphate into a glass ionomer cement. Dental Materials 2011;27:235-43.

22. Bayindir YZ, Yildiz M. Surface hardness properties of resin-modified glass ionomer cements and polyacidmodified composite resins. J Contemp Dent Pract 2004;5:42-9.

23. Abu-bakr N, Han L, Okamoto A, Iwaku M. Changes in the mechanical properties and surface texture of compomer immersed in various media. J Prosthet Dent 2000;84: 444-52.

24. Oysaed H, Ruyter IE. Water sorption and filler characteristics of composites for use in posterior teeth. $\mathrm{J}$ Dent Res 1986;65:1315-8.

25. Dunne SM, Goolnik JS, Millar BJ, Seddon RP. Caries inhibition by a resin-modified and a conventional glass ionomer cement, in vitro. J Dent 1996;24:91-4.

26. Tam LE, Chan GP, Yim D. In vitro caries inhibition effects by conventional and resin-modified glass-ionomer restorations. Oper Dent 1997;22:4-14.

27. Vermeersch G,Leloup G,Delmée M,Vreven J .Antibacterial activity of glass ionomer cements, compomers and resin composites: relationship between acidity and material setting phase. J Oral Rehabil 2005;32:368-74.

28. Young AM. "FTIR investigation of polymerization and polyacid neutralization kinetics in resin-modified glassionomer dental cements," Biomaterials 2002;23:3289-95.

29. Nicholson JW. "Chemistry of glass-ionomer cements: a review," Biomaterial 1998; 19: 485-94.

30. de Maeyer EAP, Verbeeck RMH, and Vercruysse CWJ. "Infrared spectrometric study of acid-degradable glasses," Journal of Dental Research 2002; 81:552-5.

31. Gu YW, Yap AUJ, Cheang P, Koh YL, Khor KA. Development of zirconia-glass ionomer cement composites. Journal of Non Crystalline Solids 2005; 351:508-14.

32. Moshaverinia A, Ansari S, Moshaverinia M, Roohpour N, Darr JA, Rehman I. Effects of incorporation of hydroxyapatite and fluoroapatite nanobioceramics 
into conventional glass ionomer cements (GIC). Acta Biomaterialia 2008;4:432-40.

33. Moshaverinia A, Ansari S, Movasaghi Z, Billington RW, Darr JA, Rehman IU. Modification of conventional glassionomer cements with $\mathrm{N}$-vinylpyrrolidone containing polyacids, nano-hydroxy and fluoroapatite to improve mechanical properties. Dental Materials 2008; 24:1381-90.

34. Prentice LH, Tyas MJ, Burrow MF. The effect of ytterbium fluoride and barium sulphate nanoparticles on the reactivity and strength of a glass-ionomer cement. Dental Materials 2006; 22:746-51.

35. Eisenburger M., Addy M., Rossbach A.: Acid solubility of luting cements. Journal of Dentistry 2003; 31: 137-42.

36. Jivraj SA, Kim TH, Donovan TE. Selection of luting agents, part 1. J Calif Dent Assoc 2006; 34:149-60.

37. Herrera M, Castillo A, Baca P, Carrion P. Antibacterial activity of glass-ionomer restorative cements exposed to cavity producing microorganisms. Oper Dent 1999; 24:286-91.
38. Tobias RS. Antibacterial properties of dental restorative materials: a review. Int Endod J 1988; 21:155-60.

39. Sanders BJ, Gregory RL, Moore K, Avery DR. Antibacterial and physical properties of resin modified glass ionomers combined with chlorhexidine. J Oral Rehabil 2002; 29:553-8.

40. Hammer KA, Carson CF and Riley TV. Antimicrobial activity of essential oils and other plant extracts. Journal of Applied Microbiology 1999;86:985-90.

41. Inouye S1, Takizawa $\mathrm{T}$, Yamaguchi H. Antibacterial activity of essential oils and their major constituents against respiratory tract pathogens by gaseous contact. J Antimicrob Chemother. 2001;47:565-73.

42. Hawar S.N. Activity of myrrh (commiphora molmol) essential oil on growth of candida albicans. Ibn AlHaitham J. For Pure\& Appl. Sci 2008;2:1-8.

43. Hong Li, Tian Yang, Fei-Yan Li, Yan Yao, Zhong-Min Sun. Antibacterial activity and mechanism of action of Monarda punctata essential oil and its main components against common bacterial pathogens in respiratory tract. Int J Clin Exp Pathol. 2014; 7:7389-98. 